\title{
Newly developed binocular treatment of Amblyopia using head-mounted display
}

\author{
Haeng Jin Lee ${ }^{1}$, and Seong-Joon Kim ${ }^{1,2 *}$ \\ ${ }^{1}$ Department of Ophthalmology, Seoul National University College of Medicine, Seoul, Republic of Korea \\ ${ }^{2}$ Seoul Artificial Eye Center, Seoul National University Hospital Clinical Research Institute, Seoul, Republic of Korea
}

\section{Introduction}

Amblyopia is defined as decrease of visual acuity in one eye when caused by abnormal binocular interaction or occurring in one or both eyes as a result of pattern vision deprivation during visual immaturity, for which no cause can be detected during the physical examination of the eye(s) and which in appropriate cases is reversible by therapeutic measures [1]. There are $2 \sim 5 \%$ of patients in population and the most common cause of visual impairment in children and monocular low vision in adults.

The treatment of amblyopia is monocular patching or penalization. However, there are some limitations of monocular amblyopia therapy. First, there is incomplete recovery resulting in the final vision of 20/30 in $25 \sim 60 \%$, or 2 lines worse than sound eye [2,3]. Second, there is a possibility of recurrence after withdrawal of the treatment, reported as about $25 \%$ in patients $[4,5]$. Third, the compliance is poor, especially in children [6].

Recent studies have reported that abnormal binocular interactions play a key role in amblyopia. Based on this theory, the binocularitystimulating therapies on amblyopia using perceptual learning or dichoptic stimulus presentation have been introduced [7-11]. The mechanism of dichoptic presentation is presenting the strong stimulus to the amblyopic eye and another weak stimulus to the normal fellow eye. Many types of devices are used for dichoptic presentation: Headmounted video display [12], LCD shutter glasses [13], combination of the images [14, 15], and iPad [16-19]. Based on this mechanism, we developed the new system using Head-mounted display.

\section{Material and methods}

We developed the new software program which directly targets the binocular function using dichoptic presentation. It separates the $3 \mathrm{D}$ images and controls the visual inputs into the both eyes using Head-mounted display. The genre of developed software program is the game. The game presents a split screen view, allowing independent control of the contrast and intensity of the 3D images using the 16 level of Gaussian blur method; the contrast and intensity of the 3D images increases to the amblyopic eye and decreases those to the normal fellow eye (Figure 1).

The name of game is "Ice Cream Truck", a casual shooting game throwing ice creams to the kids running towards the player. There are three levels including normal, expert and hardest level that can be selected according to the player's ability (Figure 2). This separation of $3 \mathrm{D}$ images is expected to improve the monocular visual acuity of the amblyopic eye with the reduction of suppression and strengthen the binocular fusion including stereopsis.

\section{Conclusion}

The binocular therapy using Head-mounted display seems breakthrough in amblyopia therapy. This is based on the new concept of action mechanism like stimulation of the binocular interaction and stereopsis. It is free control of parameters (contrast, brightness, resolution, etc) using Head-mounted display and dedicated application and possible to control the personalized level at beginning and during the treatment.

In addition, the newly developed binocular therapy using headmounted display is hand-held and convenient. Further investigation

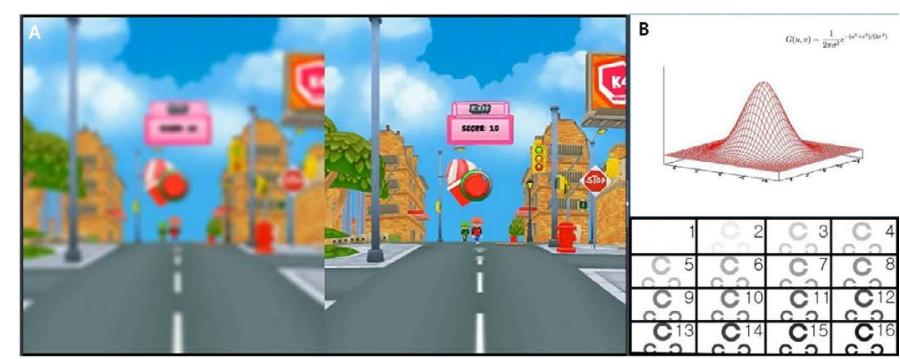

Figure 1. The developed software program separate the $3 \mathrm{D}$ images and control the visua inputs into the both eyes by increasing the contrast and intensity of the 3D target to the amblyopic eye and decreases those to the normal fellow eye. (A) Example of blur-applied screenshot of the game. (B) 16 level of Gaussian blur method used in this software program.

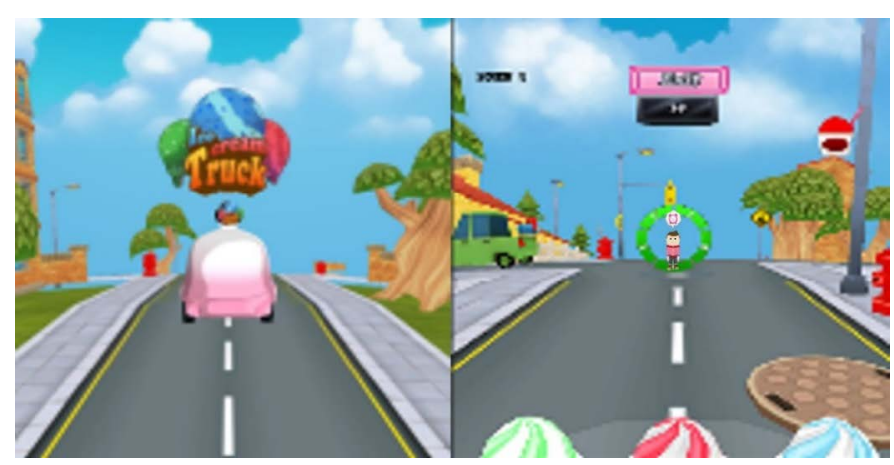

Figure 2. The software program named "Ice Cream Truck" game which is a casual shooting game throwing ice creams to the kids running towards the player.

Correspondence to: Seong-Joon Kim, Department of Ophthalmology, Seoul National University Hospital 101 Daehak-Ro, Jongno-Gu, Seoul 110-744, Republic of Korea; Tel: 82-2-2072-1979; Fax: 82-2-741-3187; E-mail: ophjun@gmail.com

Received: July 14, 2016; Accepted: July 26, 2016; Published: July 29, 2016 
is under way to prove the effectiveness in improvement of both monocular and binocular vision in children and adults with amblyopia. Furthermore, other various contents such as game, movie, or animation to improve the compliance of patients could be used in the next generation system.

\section{References}

1. GK vN. Binocular Vision and Ocular Motility. $5^{\text {th }}$ ed St Louis: Mosby 2002: 356-376.

2. Levartovsky S, Gottesman N, Shimshoni M, Oliver M (1992) Factors affecting longterm results of successfully treated amblyopia: age at beginning of treatment and age at cessation of monitoring. J Pediatr Ophthalmol Strabismus 29: 219-223. [Crossref]

3. Scott WE, Dickey CF (1988) Stability of visual acuity in amblyopic patients after visual maturity. Graefes Arch Clin Exp Ophthalmol 226: 154-157. [Crossref]

4. Holmes JM, Beck RW, Kraker RT, Astle WF, Birch EE, et al. (2004) Risk of amblyopia recurrence after cessation of treatment. J AAPOS 8: 420-428. [Crossref]

5. Bhola R, Keech RV, Kutschke P, Pfeifer W, Scott WE (2006) Recurrence of amblyopia after occlusion therapy. Ophthalmology 113: 2097-2100. [Crossref]

6. Wang J (2015) Compliance and patching and atropine amblyopia treatments. Vision Res 114: 31-40. [Crossref]

7. Hess RF, Mansouri B, Thompson B (2010) A new binocular approach to the treatment of amblyopia in adults well beyond the critical period of visual development. Restor Neurol Neurosci 28: 793-802. [Crossref]

8. Hess RF, Mansouri B, Thompson B (2011) Restoration of binocular vision in amblyopia. Strabismus 19:110-118. [Crossref]

9. Hess RF, Thompson B (2013) New insights into amblyopia: binocular therapy and noninvasive brain stimulation. J AAPOS 17: 89-93. [Crossref]
10. Hess RF, Thompson B, Black JM, Machara G, Zhang P, et al. (2012) An iPod treatment of amblyopia: an updated binocular approach. Optometry 83: 87-94. [Crossref]

11. Li RW, Young KG, Hoenig P, Levi DM (2005) Perceptual learning improves visual performance in juvenile amblyopia. Invest Ophthalmol Vis Sci 46: 3161-3168. [Crossref]

12. Knox PJ, Simmers AJ, Gray LS, Cleary M (2012) An exploratory study: prolonged periods of binocular stimulation can provide an effective treatment for childhood amblyopia. Invest Ophthalmol Vis Sci 53: 817-824. [Crossref]

13. Bossi M, Anderson EJ, Tailor V, Bex PJ, Greenwood JA, et al. (2014) An exploratory study of a novel home-based binocular therapy for childhood amblyopia. Invest Ophthalmol Vis Sci 55: ARVO E-Abstract 5981.

14. Herbison N, Cobb S, Gregson R, Ash I, Eastgate R, et al. (2013) Interactive binocular treatment (I-BiT) for amblyopia: results of a pilot study of 3D shutter glasses system. Eye 27: 1077-183. [Crossref]

15. Foss AJ, Gregson RM, MacKeith D, Herbison N, Ash IM, et al. (2013) Evaluation and development of a novel binocular treatment (I-BiT) system using video clips and interactive games to improve vision in children with amblyopia ('lazy eye'): study protocol for a randomised controlled trial. Trials 14: 145. [Crossref]

16. Birch EE, Li SL, Jost RM, Morale SE, De La Cruz A, et al. (2015) Binocular iPad treatment for amblyopia in preschool children. J AAPOS 19: 6-11. [Crossref]

17. Handa T, Ishikawa H, Shoji N, Ikeda T, Totuka S, et al. (2015) Modified iPad for treatment of amblyopia: a preliminary study. J AAPOS 19: 552-554. [Crossref]

18. Li SL, Jost RM, Morale SE, De La Cruz A, Dao L, et al. (2015) Binocular iPad treatment of amblyopia for lasting improvement of visual acuity. JAMA Ophthalmol 133: 479-480. [Crossref]

19. Li SL, Jost RM, Morale SE, Stager DR, Dao L, et al. (2014) A binocular iPad treatment for amblyopic children. Eye 28: 1246-1253. [Crossref]

Copyright: (C2016 Lee HJ. This is an open-access article distributed under the terms of the Creative Commons Attribution License, which permits unrestricted use, distribution, and reproduction in any medium, provided the original author and source are credited. 